\title{
Impact of workplace ostracism on knowledge hoarding: mediating role of defensive silence and moderating role of experiential avoidance
}

\author{
Bilal Khalid, Rimsha Iqbal and Syed Danial Hashmi ${ }^{*}$
}

\begin{abstract}
The purpose of this study is to investigate the underlying mechanism through which knowledge hoarding is triggered among ostracized employees at workplace. Drawing on conservation of resource theory, the study investigates the mediating role of defensive silence in this relationship. Further, the study also examines the moderating role of experiential avoidance between workplace ostracism and defensive silence. Using multi-layered and convenient sampling technique, data were collected from 225 employees working in the hospitality industry in Pakistan. The results revealed that workplace ostracism significantly influences employees' knowledge hoarding behavior both directly and through defensive silence. Furthermore, contrary to the expectation, the combined effect of workplace ostracism and experiential avoidance on defensive silence was found insignificant, which we have discussed. The study provides insights for managers to break the knowledge hoarding cycle and create new models for interaction and knowledge sharing among employees at workplace.
\end{abstract}

Keywords: Defensive silence, Experiential avoidance, Knowledge hoarding, Workplace ostracism

\section{Introduction}

In the epoch of knowledge-driven economies, organizations rely on the skills and knowledge of their workforce to create value for their stakeholders [45]. It is widely recognized that efficient transfer of knowledge not only facilitates organizational development but also plays an imperative role in the context of organizational sustainable competitive advantage $[1,16]$. However, not sharing knowledge and hoarding it delibrately is also a phenomenon of significant importance that prevails among organizational members [26]. Knowledge hoarding refers to a person's conscious and deliberate effort to hide the knowledge [16]. It can be seen as strategic concealment of knowledge [16] and is an accumulation of knowledge

*Correspondence: danial.hashmi@riphah.edu.pk

Faculty of Management Sciences, Riphah International University, Islamabad, Pakistan that may or may not be shared at a later stage of time [31]. Scholars found that knowledge hoarding results in destructive consequences, such as it lessens individual performance and hinders work-related interactions [8].

More recently, researchers have also tried to examine that what triggers knowledge hoarding behavior among employees? Researchers have found organizational culture and management [3] and leadership specifically the negative leadership, i.e., despotic leadership [44] as possible triggers of knowledge hoarding among employees. Likewise, researchers have also suggested workplace ostracism as a possible antecedent of knowledge hoarding behavior [55].

Research shows that ostracized employees are less engaged, full of fear and have low performance [38]. They feel less important and refrain from socialization process and thus avoid exhibiting extra role behaviors like organizational citizenship behavior and knowledge sharing 
[49] and would rather start hoarding the knowledge [56]. We, however, argue that workplace ostracism doesn't directly influence the knowledge hoarding behavior among employees. Rather, we propose defensive silence as an underlying mechanism that transforms ostracism into knowledge hoarding. Defensive silence is a proactive behavior of employees to remain silent because they feel that speaking up can be risky for his/her position within the organization and can lead to disputes [13]. Recent research suggests that employees can adopt defensive silence either to avoid confrontation with supervisor or to avoid disapproval from colleagues [51].

Employees who experience ostracism at workplace are ignored by the coworkers and the coworkers do not welcome their ideas, opinions and suggestions [43]. Employees would thus refrain from socialization with others and would start exhibiting defensive silence to avoid being rejected at workplace. This defensive silence would cause knowledge hoarding.

Conservation of resource (COR) theory [32] provides rationale for such relationship. Ostracism works as a stressor that eliminates the personal resources (time and energy) of individuals which lead them to stay silent at workplace to avoid rejection and refill the lost resources and consequently they would start exhibiting knowledge hoarding behavior.

When faced with a stressor like ostracism at workplace, employees need coping mechanisms. Using the COR framework, we propose that experiential avoidance can play an important role as a coping variable to reduce the negative relationship between workplace ostracism and defensive silence. Ostracism works as a stressor that depletes the personal resources of employees. However, those employees who have high experiential avoidance will let their pain pass and would ignore the situation as they want an escape from the ongoing situation [4]. This will help them to regain the lost resources earlier than those who have low experiential avoidance. This will reduce the negative effect of ostracism on defensive silence.

This study thus has twofold objective. Firstly, we have examined defensive silence as the possible mechanism between workplace ostracism and knowledge hoarding. Secondly, we proposed experiential avoidance as a moderator between workplace ostracism and defensive silence. The study adds to the existing body of knowledge in certain ways: Firstly, we add to the scarce literature that examines the underlying mechanisms of transformation of certain stressors into knowledge hoarding. Secondly, we add to the existing literature examining the variables that can help to cope with the stressors at workplace by proposing experiential avoidance as a coping strategy from ostracism to reduce defensive silence.
Lastly our study answers to the recent calls for future research on the examination of antecedents and mechanisms that lead to knowledge hoarding.

\section{Theory and hypothesis \\ Workplace ostracism and knowledge hoarding}

Researchers in earlier studies stated that knowledge hoarding is one of the most critical problems that is being faced by organizations because it hinders organizational success hindered organizations from success [26] and also effects the process of individuals' growth within organizations [14]. Scholars defined knowledge hoarding as the intentional and strategic concealment of information and knowledge by an individual [16].

Connelly, Zweig, Webster and Trougakos [12] highlighted that knowledge hoarding is a completely different phenomena from knowledge hiding. Scholars stated that knowledge hiding is based on other individuals' request to provide relevant knowledge. Whereas, in knowledge hoarding, as such no request is made by others regarding sharing of accumulated knowledge [47]. Research suggests that knowledge hoarding and hiding are not inherently negative behaviors like incivility or any other counter-productive work behavior. People can hoard knowledge with a self-benefit goal rather having an objective to conceal deliberately [46].

One of the important factors leading toward knowledge hoarding behavior at workplace is employee's frustration due to some unpleasant event. Scholars in providing the directions to future researchers documented that workplace ostracism might be a potential determinant of knowledge hoarding at workplace because the phenomena of ostracism at workplace is not new and employees experience it generally $[19,55]$.

Workplace ostracism (WOS) refers to the extent to which employees are ignored and excluded by other organizational members, and as a result, the coworkers do not welcome their ideas, opinions and suggestions [43]. According to Yang and Treadway [53], ostracism is an excruciating phenomenon at workplace with or without any malicious intentions. Scholar further stated that the outcomes of ostracism are both behavioral and psychological, and they create risk at workplace, especially in the service-oriented organizations. Thus, based on conservation of resource theory (COR) [32] the present study attempts to examine the association between workplace ostracism and knowledge hoarding.

COR theory postulated that an employee would protect his or her remaining resources in an organization by using specific measures such as depersonalization, reducing efforts and knowledge hoarding. Nowak [42] stated that employees at workplace hoard their knowledge by dint of fear that if they share their knowledge, then their 
power over it curtails. In the similar manner, Evans et al. [16] argued that the ostracized employees at workplace hoard knowledge because they feel that controlling more knowledge to increase personal bargaining power could be a better way to deal with workplace ostracism. Thus, based on aforementioned arguments it is hypothesize that:

Hypothesis 1 Workplace ostracism is positively associated with knowledge hoarding.

\section{Mediating role of defensive silence}

Gkorezis, Panagiotou and Theodorou [21] stated that employees become silent and withhold significant information due to the practice of workplace ostracism in organizations. Dyne et al. [15] documented that employee silence is a multi-dimensional construct and has three dimensions, i.e., acquiescent silence, defensive silence and pro-social silence. Milliken, Morrison and Hewlin [40] define defensive silence as withholding relevant ideas, information or opinions as a form of self-protection, based on fear. Although, the term ostracism has gained popularity and researchers have studied its outcomes at workplace through various underlying mechanisms, e.g., conflict, organizational identification, self-esteem and envy $[9,10,49]$ but still as such no study has examined the intervening role of defensive silence; a dimension of employee silence with ostracism and its outcomes. Milliken, Morrison and Hewlin [40] argued that defensive silence is detrimental within organizational context as it generates negative work-related outcomes. Similarly, when employees feel that their information and opinions will not be appreciated by others or may bring negative or unpleasant results so then they do not express themselves fully and engage in defensive silence.

In line with conservation of resource theory (COR) [32], ostracized employees at the workplace have a fear of losing valued resources such as social relationship, social support and the opportunity for quick growth at workplace in organizations. Thus, after this unexpected situation employee becomes more proactive and used defensive silence as a strategy for the restoration of lost resources by consciously refraining them from sharing their knowledge and opinions with others [52]. The individuals also claim that the knowledge they gained and possessed during their working tenure as their "property right" and to maintain their existence in the organizational context and to regain their "personal mastery", they indulge in defensive silence and withhold information rather than to share it with others in an organization [33]. Thus, by integrating the aforementioned arguments, this study has hypothesized that:
Hypothesis 2 Defensive silence mediates the relationship between workplace ostracism and knowledge hoarding.

\section{Experiential avoidance as moderator}

Hayes, Strosahl and Wilson [29] defined experiential avoidance as the propensity to engage in behaviors that seeks to change the form, frequency or content of unwanted thoughts, feelings and sensations. Extant research has theorized and conceptualized experiential avoidance as a negative behavior that is highly correlated with self-harm [4]. Scholars further stated that experiential avoidance results in several negative mental health consequences such as high levels of stress, hopelessness and psychosocial dysfunction [28].

On contrary, few scholars suggested that the phenomenon of experiential avoidance is unique in its nature to stress coping mechanism [34] because experiential avoidance as a regulating strategy mitigates the intensity of stressors that affect individuals' behaviors [22].

Extensive literature on ostracism revealed that it has several physical, psychological and organizational outcomes $[43,48,55]$. According to scholars, workplace ostracism experience is very painful as individuals have a fear that their ideas and views will not be appreciated due to which they have to face stress, hopelessness and embarrassment; thus, for self-protection from this fear individuals indulge in silence [25]. Prior researchers stated that coping is a best way to deal with stressful events as it refers to the way an individual approach or respond to the stressful situations [37]. Furthermore, Carver et al. [7] stated that along with other dimensions of coping like problem focused and emotions focused, the avoidance focused coping is also a significant dimension that is used for coping with stressful situations, as the basic purpose of this approach is to dampen the thoughts and emotions associated with stressful events.

Thus, based on conservation of resource theory (COR) [32] energy as an intrinsic resource of employees at workplace should be replenished often to perform assigned tasks and people must invest resources in order to protect against potential resource loss, recover from resource losses and gain resources. Thus, at workplace the employees use experiential avoidance as a coping strategy to replenish the lost resources by regulating their thoughts, behaviors and feelings and disengage them mentally from the stress caused by ostracism at workplace. Therefore, based on aforementioned arguments it is asserted that those employees who would not opt experiential avoidance as a regulating strategy than their resource depletion would be high. Whereas, those employees who adopt experiential avoidance as a deliberate tactic then 
their energy and resource depletion would be low and resultantly they would not go toward defensive silence. Hence, researchers hypothesized that:

Hypothesis 3 Experiential avoidance mitigates the effect of workplace ostracism on defensive silence in such a way that the relationship is weak when experiential avoidance is high.

\section{Methods}

\section{Participants and procedures}

The selected population for the study was employees working in hospitality industry of Pakistan. The hospitality industry of Pakistan is constantly growing [39]. The hospitality industry has a workforce of around 200,000 people, majority of which is skilled labor [41]. The study was conducted on employees of four and five star hotels because in services sector the hospitality industry is a suitable industry for knowledge sharing due to high customer engagement with the staff [54]. If employees exchange and transfer their experience and knowledge, then ultimately it will enhance the employees' capability and consequently affects the overall organizational performance that leads to sustainable competitive advantage [35]. Lack of desire to share knowledge and hoard it among employees in hospitality industry has severe consequences. Therefore, the present study has taken hospitality industry to identify the factors that may inhibit knowledge sharing practices among the employees.

Using multi-layered and convenient sampling technique, questionnaires were distributed among selected employees working in hospitality industry as mentioned above. Respondents voluntarily participation, anonymity and confidentiality were ensured to the respondents before collection of data. Convenience sampling technique is the most common and widely used technique in management science research. One potential problem with primary data collection is common method bias. In order to combat common method bias, researchers have suggested using time lags in collection of data [6]. So, in order to avoid common method bias, we collected data using time lags. Time interval of 6 weeks was given in each time lag. In the first time lag (T1), respondents were asked to provide their demographic information along with responses on items measuring workplace ostracism (IV) and experiential avoidance (moderator). In the second time lag (T2), participants were asked about defensive silence (mediator). For the third time lag (T3), the data were collected about knowledge hoarding (DV). To uphold the respondent's privacy and for the sake of matching the same respondents' responses from T1, T2 and T3, the respondents were assigned codes. This leads to access same respondents with their consent in T2 and T3, accordingly.

In the T1, 300 usable responses were received out of 400 questionnaires distributed constituting a response rate of $75 \%$. The unusable responses were either improperly filled or had missing values greater than $10 \%$ of the total items. Give reason for this for the T2, questionnaires were sent only to those who responded in the first phase, and finally 240 usable questionnaires were received back constituting the response rate of $60 \%$. In the third phase, same procedure followed, finally 225 usable questionnaires received back were considered for statistical analysis; yield a response rate of $56 \%$. The sample included $49 \%$ male and $51 \%$ female. $46 \%$ of them were in between 20 and 35 years of age, whereas $54 \%$ of them were in between 36 and 55 years of age. Around 56\% of the respondents were supervisory or first line managers. $52 \%$ of the total respondents had qualification masters or above.

\section{Measures}

All variables were measured using self-reported instruments. Responses for all variables were assessed using a 7-point Likert response scale, where 1 corresponds to "strongly disagree" and 7 corresponds to "strongly agree." The complete scale used in the study along with the sources is attached in the appendix.

\section{Workplace ostracism}

Workplace ostracism was measured using a ten-item scale based on the studies by Ferris et al. [17]. A sample item was "Others ignored you at work." The Cronbach's alpha of the instrument was 96 .

\section{Defensive silence}

Defensive silence was measured using a five-item instrument based on the studies by Dyne et al. [15]. A sample item was "I withhold relevant information due to fear." The alpha reliability of defensive silence was .95 .

\section{Experiential avoidance}

Experiential avoidance was measured through 15-items of brief experiential avoidance questionnaire (BEAQ) developed by Gámez et al. [20]. A sample item was "The key to a good life never feeling any pain". The Cronbach's alpha of the instrument was 96 .

\section{Knowledge hoarding}

Knowledge hoarding was measured with four-item instrument based on the studies by Evans et al. [16]. Sample item from this scale included "I keep news about what I am doing secret from others until the appropriate time." 
Table 1 One-way ANOVA for identification of control variables

\begin{tabular}{lccccc}
\hline Demographics & \multicolumn{2}{c}{ Defensive silence } & & \multicolumn{2}{c}{ Knowledge hoarding } \\
\cline { 2 - 3 } & $\boldsymbol{f}$ statistics & $\boldsymbol{p}$ value & & $\boldsymbol{f}$ statistics & $\boldsymbol{p}$ value \\
\hline Gender & .96 & .33 & & .01 & .91 \\
Age & 1.92 & .08 & & 4.78 & .00 \\
Management level & 7.69 & .00 & & 14.21 & .00 \\
Qualification & 3.28 & .04 & & 8.73 & .00 \\
\hline
\end{tabular}

$n=225$

The internal consistency reliability of knowledge hoarding was .92.

\section{Control variables}

Gender, age, management level and qualification were used as control variables because of their possible effects on knowledge hoarding and defensive silence. A one-way ANOVA was used to identify the control variables.

Results of one-way ANOVA in Table 1 revealed that there was significant variation in defensive silence based on employees' management level $(f=7.69, p<.05)$ and qualification $(f=3.28, p<.05)$. Table 1 also shows that there was significant variation in knowledge hoarding based on employees' age $(f=4.78, p<.05)$, management level $(f=14.21, p<.05)$ and qualification $(f=8.73, p<.05)$. Thus, these three demographic variables will be controlled in further analysis. Other demographic variables such as gender had no significant impact on defensive silence and knowledge hoarding (Fig. 1).

\section{Results}

Preliminary analysis

Table 2 shows the mean, standard deviation and correlation analysis of the study variables. According to the results presented in Table 2, the workplace ostracism is positively associated with knowledge hoarding and defensive silence, i.e., $(r=.58, p<.001)$ and $(r=.69$, $p<.001)$, respectively, thus providing initial support to proposed hypothesis. Table 2 also depicts that experiential avoidance is positively correlated with workplace ostracism, i.e., $(r=.70, p<.001)$. As all the values of correlation coefficient " $\mathrm{r}$ " lies within the range of .3 to .7 ; thus, there is no issue of multicollinearity in the data.

\section{Measurement model}

Partial least squares (PLS) method [24] was used to perform Confirmatory Factor Analysis (CFA) so as to justify the measurement model [2] which consisted of four (4) latent variables: Workplace ostracism (WOS), defensive silence (DS), knowledge hoarding (KH) and experiential avoidance (EA). Thus, based on the results of CFA presented in Fig. 2 all the indicators with outer loadings between .60 and .94 were retained because of their contribution to content validity.

The results of internal consistency (alpha values), composite reliability met the threshold value $(0.7)$ are reported in Table 3. For convergent validity, AVE (average variance extracted) was calculated holding threshold value (greater than 0.5 ). Thus, convergent validity is established.

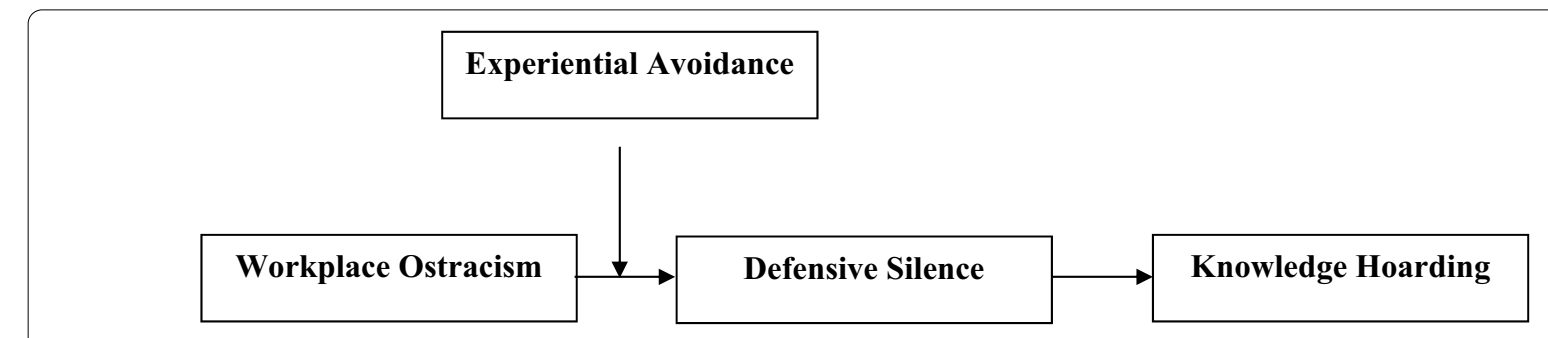

Fig. 1 Research model

Table 2 Descriptive statistics and correlation coefficients of variables

\begin{tabular}{llllll}
\hline Variables & Mean & SD & $\mathbf{1}$ & $\mathbf{2}$ & $\mathbf{3}$ \\
\hline 1 WOS & 4.44 & 1.54 & 1 & & $\mathbf{4}$ \\
2 DS & 4.06 & 1.63 & $.69^{* * *}$ & 1 & $.71^{* * *}$ \\
$3 \mathrm{KH}$ & 4.26 & 1.66 & $.58^{* * *}$ & $.63^{* * *}$ & $.34^{* * *}$ \\
4 EA & 4.52 & 1.29 & $.70^{* * *}$ & 1 \\
\hline
\end{tabular}

WOS workplace ostracism, DS defensive silence, $K H$ knowledge hoarding, EA experiential avoidance, ${ }^{*} p<.05,{ }^{* *} p<.01,{ }^{* * *} p<.001, n=225$ 


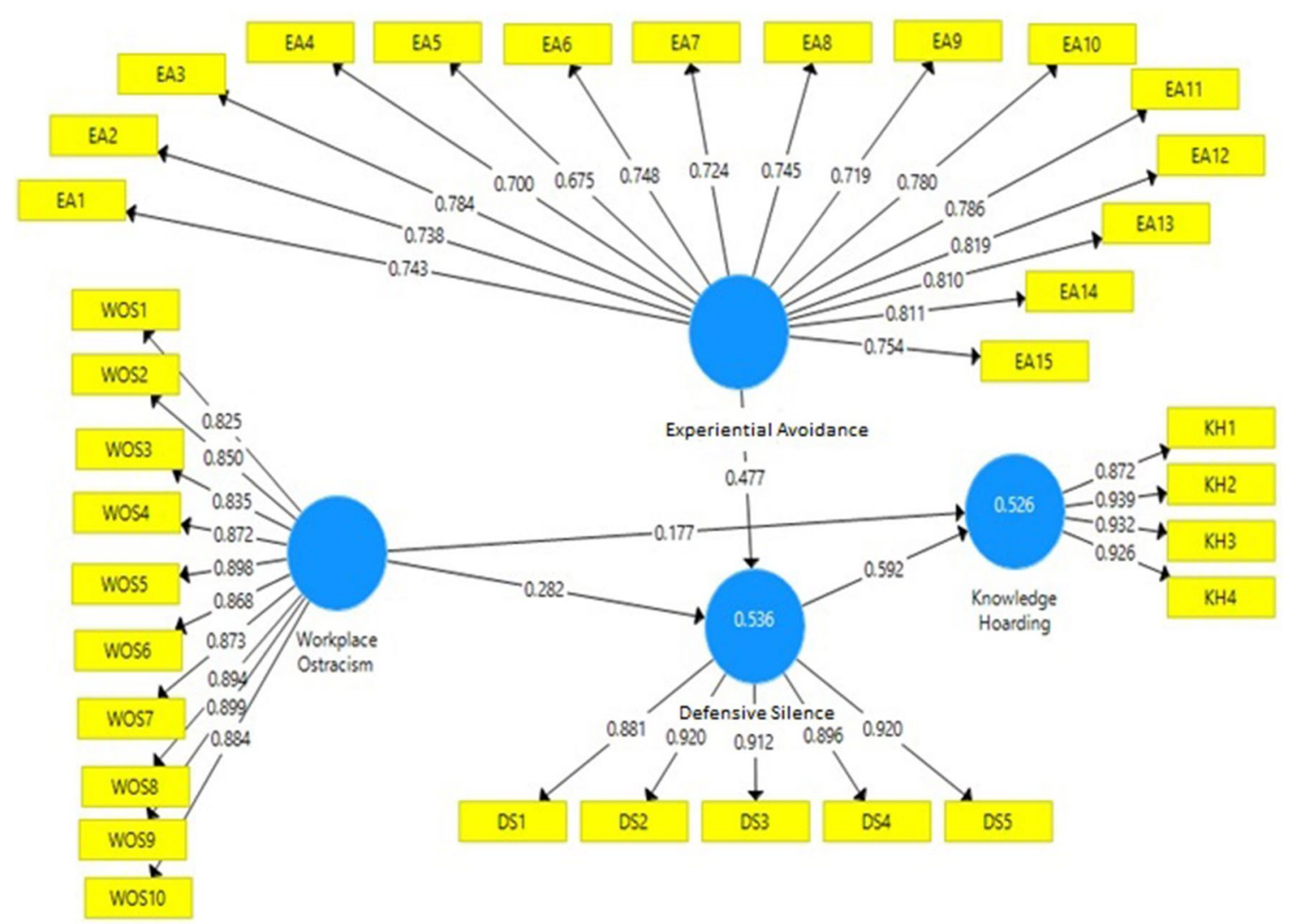

Fig. 2 Measurement model

After verifying the convergent validity, the discriminant validity was assessed through Fornell and Larcker's criterion [18] and through HTMT (hetrotrait-monotrait) ratio [30]. Based on the results presented in Table 4, the diagonal values are high as compared to the other values in their own rows and columns, which give initial support to establish the discriminant validity of the measures [24].

Furthermore, Table 5 also shows that the HTMT ratios of constructs met the threshold limit and are lower than .90 [30]. Therefore, the discriminant validity of the measures is established.

\section{Hypothesis testing}

Direct and indirect effects were determined through Process Macro given by Hayes [27]. The results presented in Table 6 depict that workplace ostracism is positively associated with knowledge hoarding $(\beta=.57, p<.00)$; thus, H1 is supported. Furthermore, based on the results presented in Table 6 the indirect effect (.41) of defensive silence between workplace ostracism and knowledge hoarding lies within .28 and .55 and there is no zero in the $95 \%$ confidence interval. Therefore, it is concluded that defensive silence mediates the relationship between workplace ostracism and knowledge hoarding. Thus, H2 is supported.

Moderated regression analysis technique developed by Cohen, West and Aiken [11] was used to investigate the $\mathrm{H} 3$ of study. The $\mathrm{H} 3$ of the study was that experiential avoidance mitigates the relationship between workplace ostracism and defensive silence in such a way that this relationship is weaker when experiential avoidance is high. Based on results presented in Table 7 , the interaction term is insignificant $(\beta=.01, p=\mathrm{ns})$. Hence, it was found that $\mathrm{H} 3$ is not supported.

\section{Discussion}

Based on conservation of resource theory [32], this study has pursued to determine the antecedents of knowledge hoarding among employees. Empirical evidences supported most of the proposed hypothesis of the present study.

The first hypothesis (H1) of present study that workplace ostracism is positively associated with knowledge hoarding was supported. Here, the results are in accordance with the findings of Sarwar et al. [44], who 
Table 3 Measurement model (estimates)

\begin{tabular}{|c|c|c|c|c|c|}
\hline Constructs & Items & Loadings & Cronbach alpha & $\begin{array}{l}\text { Composite reliability } \\
\text { (CR) }\end{array}$ & $\begin{array}{l}\text { Average } \\
\text { variance } \\
\text { extracted (AVE) }\end{array}$ \\
\hline \multirow[t]{9}{*}{ Workplace ostracism (WOS) } & WOS1 & .86 & .96 & .97 & .76 \\
\hline & WOS2 & .85 & & & \\
\hline & WOS3 & .84 & & & \\
\hline & WOS4 & .87 & & & \\
\hline & WOS6 & .89 & & & \\
\hline & WOS7 & .86 & & & \\
\hline & WOS8 & .87 & & & \\
\hline & WOS9 & .89 & & & \\
\hline & WOS10 & .88 & & & \\
\hline \multirow[t]{5}{*}{ Defensive silence (DS) } & DS1 & .88 & .95 & .96 & .82 \\
\hline & DS2 & .92 & & & \\
\hline & DS3 & .91 & & & \\
\hline & DS4 & .89 & & & \\
\hline & DS5 & .92 & & & \\
\hline \multirow[t]{4}{*}{ Knowledge hoarding $(\mathrm{KH})$} & $\mathrm{KH} 1$ & .87 & .94 & .96 & .84 \\
\hline & $\mathrm{KH} 2$ & .94 & & & \\
\hline & $\mathrm{KH} 3$ & .93 & & & \\
\hline & $\mathrm{KH} 4$ & .93 & & & \\
\hline \multirow[t]{15}{*}{ Experiential avoidance (EA) } & EA1 & .74 & .95 & .95 & .57 \\
\hline & EA2 & .74 & & & \\
\hline & EA3 & .78 & & & \\
\hline & EA5 & .70 & & & \\
\hline & EA5 & .68 & & & \\
\hline & EA6 & .75 & & & \\
\hline & EA7 & .72 & & & \\
\hline & EA8 & .75 & & & \\
\hline & EA9 & .72 & & & \\
\hline & EA10 & .78 & & & \\
\hline & EA11 & .79 & & & \\
\hline & EA12 & .82 & & & \\
\hline & EA13 & .81 & & & \\
\hline & EA14 & .81 & & & \\
\hline & EA15 & .75 & & & \\
\hline
\end{tabular}

Table 5 Discriminant validity (HTMT ratio)

\begin{tabular}{|c|c|c|c|c|c|c|c|c|c|}
\hline & & & & & & & & & \\
\hline & & & & & Constructs & 1 & 2 & 3 & 4 \\
\hline & & & & & 1 WOS & & & & \\
\hline & nant & validity & (Fornell and & Lacker's & $2 \mathrm{DS}$ & 0.720 & & & \\
\hline criterion) & & & & & $3 \mathrm{KH}$ & 0.610 & 0.754 & & \\
\hline Constructs & 1 & 2 & 3 & 4 & $4 \mathrm{EA}$ & 0.879 & 0.751 & 0.534 & \\
\hline 1WOS & 0.870 & & & & $\begin{array}{l}\text { WOS workpla } \\
\text { experiential a }\end{array}$ & $\begin{array}{l}15 \mathrm{~m}, \mathrm{DS} d \\
n=225\end{array}$ & 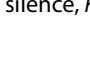 & . & \\
\hline $2 \mathrm{DS}$ & 0.689 & 0.906 & & & & & & & \\
\hline $3 \mathrm{KH}$ & 0.584 & 0.714 & 0.918 & & & & & & \\
\hline $4 \mathrm{EA}$ & 0.853 & 0.717 & 0.524 & 0.757 & impacts $k$ & dge $h$ & g. Acc & to $\mathrm{s}$ & the \\
\hline
\end{tabular}


Table 6 Results of direct and indirect effects

\begin{tabular}{|c|c|c|c|c|}
\hline Predictors & $\beta$ & SE & $T$ & $P$ \\
\hline Workplace ostracism knowledge hoarding & .57 & .06 & 9.74 & .00 \\
\hline Workplace ostracism defensive silence & .71 & .05 & 13.60 & .00 \\
\hline Defensive silence knowledge hoarding & .57 & .06 & 8.92 & .00 \\
\hline $\begin{array}{l}\text { Workplace ostracism defensive silence knowledge hoard- } \\
\text { ing }\end{array}$ & .16 & .07 & 2.33 & .02 \\
\hline \multirow[t]{2}{*}{ Boot strap results for indirect effect } & Indirect effect & $\begin{array}{l}\mathrm{LL} 95 \% \\
\mathrm{Cl}\end{array}$ & $\begin{array}{l}\text { UL } 95 \% \\
\mathrm{Cl}\end{array}$ & \\
\hline & .41 & .28 & .55 & \\
\hline
\end{tabular}

Un-standardized regression coefficients reported. Bootstrap sample size 5000. LL lower limit, Cl confidence interval, UL upper limit

Table 7 Moderated regression analysis

\begin{tabular}{|c|c|c|c|}
\hline \multirow[t]{2}{*}{ Predictors } & \multicolumn{3}{|c|}{ Defensive silence } \\
\hline & $\bar{\beta}$ & $R^{2}$ & $\Delta R^{2}$ \\
\hline \multicolumn{4}{|l|}{ Step 1} \\
\hline Control variable & & .05 & \\
\hline \multicolumn{4}{|l|}{ Step 2} \\
\hline Workplace ostracism & $.48^{* * *}$ & .52 & $.47^{* * *}$ \\
\hline Experiential avoidance & $.38^{* * *}$ & & \\
\hline \multicolumn{4}{|l|}{ Step 3} \\
\hline Interaction term (WOS*EA) & $.01 \mathrm{~ns}$ & .52 & $.00 \mathrm{~ns}$ \\
\hline
\end{tabular}

it leads to counterproductive work behavior and workplace deviant behavior [9]. Thus, based on COR theory the findings elucidate that the employee victim of ostracism at workplace assumed that knowledge hoarding is a better way to deal with ostracism because by hoarding knowledge they may regain their lost resources. Burkhardt and Brass [5] further stated that, knowledge is regarded as a significant organizational resource; therefore, an employee could improve his/her power and influence at workplace by hoarding knowledge. The results are somehow consistent with the findings of Zhao and Xia [55] that found significant curvilinear relationship between workplace ostracism and knowledge hoarding.

The results for the mediating role of defensive silence in the relationship between workplace ostracism and knowledge hoarding were in the expected direction, thus confirming the second hypothesis (H2) of study. The results are in accordance with Wu et al. [50] study in which scholars revealed workplace ostracism as a potential determinant of defensive silence (a facet of employee silence). The scholars further supported the argument that ostracized employees at workplace try to protect themselves from being ignored and thus adopted the strategy of defensive silence. Jahanzeb et al. [33] stated that individuals claim the knowledge (both theoretical and practical) that they have gained in an organization at different times as their personal resource. The scholars further stated that when individuals feel that their position is not secure in an organization then they indulge in defensive silence and used knowledge hoarding as a weapon to maintain their existence in the organization.

In addition to the aforementioned studies, the findings are also consistent with COR theory which postulate that individuals tried to retain their position in organization by protecting their depleted resources. Therefore, at workplace the ostracized employees try to protect them by adopting the tactic of defensive silence and eventually hoard their knowledge only for the sake of regaining exhausted resources.

Result of moderating role of experiential avoidance in the relationship between workplace ostracism and defensive silence was found insignificant; thus, the third hypothesis (H3) is not supported. This contradictory result is explained through the study of Vladimir and Williams (2018) in which scholars stated that in hospitality sector the fontline employees are in frequent contact with customers and are responsible to handle customer's problems for providing quality services. Kim [36] further stated that due to a frequent contact with difficult and demanding customers the hospitality service agents are often required to demonstrate emotional labor. According to scholars, the emotional labor leads to emotional exhaustion in which the individuals perceived that there all emotional resources have been exhausted that result in lack of impulse and even a fear of working [23]. Similarly, Wu and colleagues [50] further stated that workplace ostracism caused emotional exhaustion and depressed mood at workplace. Thus, the ostracized employees at workplace due to intense emotional exhaustion just demonstrate silence and do not adopt the deliberate coping tactic of emotional avoidance. Therefore, contrary to expectations in the present study, the high experiential avoidance does not lessen 
the impact of workplace ostracism on defensive silence because the employees demonstrate low emotional avoidance and take longer time to cope with workplace ostracism.

\section{Conclusions}

The research developed a model to analyze boundary condition of experiential avoidance, under which ostracized employees' at workplace might keep exercise silence to hoard their knowledge, although the same not formally requested by others. On the basis of results, researchers found that workplace ostracism leads to silence, ultimately resulted in knowledge hoarding. The current study conducted on hospitality industry of Pakistan, specific focus on four and five stars hotels. In nutshell, our findings extend the literature of workplace ostracism and knowledge hoarding through the lens of conversation of resource theory. Furthermore, findings also shed light on boundary condition of experiential avoidance, as it is insignificant effect on the relationship of workable ostracism and knowledge hoarding. Moreover, research study also provides several paths for managers to mitigate knowledge hoarding behaviors of employees at workplace within hospitality sector.

The findings of this study have clear implications for managers, as they need to monitor and control the exhibition of workplace-ostracized behavior exhibited by supervisors because ostracized employees generally hoard knowledge that is detrimental for the organizations and its growth. The managers should diminish the phenomenon of workplace ostracism completely by providing training to supervisors to demonstrate empathy with subordinates and to be aware of the consequences of maltreatment. Managers must have a look on the employees' behavior and identify those employees that exhibit silent behavior because if employees are silent then it means that they might not share important knowledge they may have. The managers can also encourage the exhibition of employee voice behavior by developing Employee Assistance Plan (EAP) that assist employees to deal with the mistreatment and better adapt to the organization's environment. The managers should also develop strategies to increase experiential avoidance that assist individuals in coping with workplace ostracism.

Along with the fruitful insights regarding determinants of knowledge hoarding at workplace, the study also has certain limitations that may be address by future scholars. First, data were collected only from hospitality industry of Pakistan and was based on self-reported measure. Due to self-reported measures, there is little chances of common method bias, researchers conducted study in time lag, in order to reduce CMB effect. In future, data can be collected through dyadic relation at workplace between employees and managers. Second, the data were collected from a small sample size of 225 respondents; therefore, the future researchers may expand the sample size to get extensive information on the matter. Third, as in present study the only defensive silence, a dimension of employee silence was used as an underlying mechanism due to which workplace ostracism leads to knowledge hoarding; therefore, future researchers may also examine the intervening role of other dimensions of employee silence, i.e., acquiescent silence and pro-social silence in the proposed research model.

\section{Abbreviations}

COR: conservation of resource; DS: defensive silence; EA: experiential avoidance; $\mathrm{KH}$ : knowledge hoarding; WOS: workplace ostracism.

\section{Acknowledgements}

Not applicable.

\section{Author's contribution}

The idea was conceptualized by BK. RI was responsible for the literature review and writing. BK, RI and SDH were involved in data collection. Data analysis was conducted by BK. BK contributed to writing original draft. SDH was involved in over-viewing the paper and writing-review and editing. All authors read and approved the final manuscript.

Funding

No funding has been availed for the study.

\section{Availability of data and materials}

Primary data were collected for the study. The datasets used and analyzed during the current study are available from the corresponding author on reasonable request.

\section{Competing interests}

Authors declare that there are no competing interests.

Received: 23 July 2020 Accepted: 2 November 2020 Published: 8 December 2020

\section{References}

1. Alnaimi AMM, Rjoub H (2019) Perceived organizational support, psychological entitlement, and extra-role behavior: the mediating role of knowledge hiding behavior. J Manag Organ. https://doi.org/10.1017/ jmo.2019.1

2. Anderson JC, Gerbing DW (1988) Structural equation modeling in practice: a review and recommended two-step approach. Psychol Bull 103(3):411

3. Bilginoğlu E (2019) Knowledge hoarding: a literature review. Manag Sci Lett 9(1):61-72

4. Brereton A, McGlinchey E (2020) Self-harm, emotion regulation, and experiential avoidance: a systematic review. Arch Suic Res 24(sup1):1-24

5. Burkhardt ME, Brass DJ (1990) Changing patterns or patterns of change: the effects of a change in technology on social network structure and power. Adm Sci Q 35(1):104-127

6. Carmeli A, Reiter-Palmon R, Ziv E (2010) Inclusive leadership and employee involvement in creative tasks in the workplace: the mediating role of psychological safety. Creat Res J 22(3):250-260

7. Carver CS, Scheier MF, Weintraub JK (1989) Assessing coping strategies: a theoretically based approach. J Pers Soc Psychol 56(2):267

8. Černe M, Nerstad CG, Dysvik A, Škerlavaj M (2014) What goes around comes around: knowledge hiding, perceived motivational climate, and creativity. Acad Manag J 57(1):172-192 
9. Chung YW (2015) The mediating effects of organizational conflict on the relationships between workplace ostracism with in-role behavior and organizational citizenship behavior. Intl J Conf Manag 26(4):366-385

10. Chung YW (2017) The role of person-organization fit and perceived organizational support in the relationship between workplace ostracism and behavioral outcomes. Austral J Manag 42(2):328-349

11. Cohen P, West SG, Aiken LS (2014) Applied multiple regression/correlation analysis for the behavioral sciences. Psychology Press, London

12. Connelly CE, Zweig D, Webster J, Trougakos JP (2012) Knowledge hiding in organizations. J Organ Behav 33(1):64-88

13. De Graaf $\mathrm{G}$ (2019) What works: the role of confidential integrity advisors and effective whistleblowing. Int Public Manag J 22(2):213-231

14. Durst S, Zieba M (2019) Mapping knowledge risks: towards a better understanding of knowledge management. Knowl Manag Res Pract 17(1):1-13

15. Dyne LV, Ang S, Botero IC (2003) Conceptualizing employee silence and employee voice as multidimensional constructs. J Manag Stud 40(6):1359-1392

16. Evans JM, Hendron MG, Oldroyd JB (2014) Withholding the ace: the individual-and unit-level performance effects of self-reported and perceived knowledge hoarding. Organ Sci 26(2):494-510

17. Ferris DL, Brown DJ, Berry JW, Lian H (2008) The development and validation of the Workplace Ostracism Scale. J Appl Psychol 93(6):1348

18. Fornell C, Larcker DF (1981) Evaluating structural equation models with unobservable variables and measurement error. J Mark Res 18(1):39-50

19. Fox S, Stallworth LE (2005) Racial/ethnic bullying: exploring links between bullying and racism in the US workplace. J Vocat Behav 66(3):438-456

20. Gámez W, Chmielewski M, Kotov R, Ruggero C, Suzuki N, Watson D (2014) The brief experiential avoidance questionnaire: development and initial validation. Psychol Assess 26(1):35

21. Gkorezis P, Panagiotou M, Theodorou M (2016) Workplace ostracism and employee silence in nursing: the mediating role of organizational identification. J Adv Nurs 72(10):2381-2388

22. Gloster AT, Klotsche J, Chaker S, Hummel KV, Hoyer J (2011) Assessing psychological flexibility: what does it add above and beyond existing constructs? Psychol Assess 23(4):970

23. Grandey AA (2003) When "the show must go on": surface acting and deep acting as determinants of emotional exhaustion and peer-rated service delivery. Acad Manag J 46(1):86-96

24. Hair JF, Ringle CM, Sarstedt M (2011) PLS-SEM: indeed a silver bullet. J Market Theory Pract 19(2):139-152

25. Hales AH, Kassner MP, Williams KD, Graziano WG (2016) Disagreeableness as a cause and consequence of ostracism. Pers Soc Psychol Bull 42(6):782-797

26. Hansen DD, Date HI, Bødker M (2012) Knowledge-hoarding. https://resea rch-api.cbs.dk/ws/portalfiles/portal/58415330/deniz_d_hansen.pdf. Accessed on 12th Oct 2019.

27. Hayes AF (2013). Model templates for PROCESS for SPSS and SAS. http:// www.personal.psu.edu/jxb14/M554/specreg/templates.pdf. Accessed on 13th Aug 2019

28. Hayes SC, Luoma JB, Bond FW, Masuda A, Lillis J (2006) Acceptance and commitment therapy: model, processes and outcomes. Behav Res Ther 44(1):1-25

29. Hayes SC, Strosahl KD, Wilson KG (1999) Acceptance and commitment therapy: an experiential approach to behavior change. Guilford Press, New York

30. Henseler J, Ringle CM, Sarstedt M (2015) A new criterion for assessing discriminant validity in variance-based structural equation modeling. J Acad Mark Sci 43(1):115-135

31. Hislop D (2003) Linking human resource management and knowledge management via commitment: a review and research agenda. Employee Relat 25(2):182-202

32. Hobfoll SE (1989) Conservation of resources: a new attempt at conceptualizing stress. Am Psychol 44(3):513

33. Jahanzeb S, Fatima T, Malik MAR (2018) Supervisor ostracism and defensive silence: a differential needs approach. Eur J Work Organ Psychol 27(4):430-440
34. Karekla M, Panayiotou G (2011) Coping and experiential avoidance: unique or overlapping constructs? J Behav Ther Exp Psychiatry 42(2):163-170

35. Kearns GS, Lederer AL (2003) A resource-based view of strategic IT alignment: how knowledge sharing creates competitive advantage. Decis Sci 34(1):1-29

36. Kim HJ (2008) Hotel service providers' emotional labor: the antecedents and effects on burnout. Int J Hosp Manag 27(2):151-161

37. Lazarus RS (1966) Psychological stress and the coping process. McGrawHill, New York

38. Leung AS, Wu LZ, Chen YY, Young MN (2011) The impact of workplace ostracism in service organizations. Int J Hosp Manag 30(4):836-844

39. Majid A, Yasir M, Yousaf Z, Qudratullah H (2019) Role of network capability, structural flexibility and management commitment in defining strategic performance in hospitality industry. Int J Contemp Hosp Manag 31(8):3077-3096. https://doi.org/10.1108/JJCHM-04-2018-0277

40. Milliken FJ, Morrison EW, Hewlin PF (2003) An exploratory study of employee silence: issues that employees don't communicate upward and why. J Manag Stud 40(6):1453-1476

41. NAVTTC (2019) A report on situational analysis of hospitality industry. Publisher, NAVTTC

42. Nowak A (2013) Infectious: how to connect deeply and unleash the energetic leader within. Skyhorse Publishing Inc., New York

43. Robinson SL, O'Reilly J, Wang W (2013) Invisible at work: an integrated model of workplace ostracism. J Manag 39(1):203-231

44. Sarwar,A, Khan MM, Mujtaba BG (2017) despotic leadership, workplace ostracism and knowledge hoarding: a serial mediation model. SAM Adv Manag J (07497075) 82(4)

45. Serenko A (2013) Meta-analysis of scientometric research of knowledge management: discovering the identity of the discipline. J Knowl Manag 17(5):773-812

46. Silva de Garcia P, Oliveira M, Brohman K (2020) Knowledge sharing, hiding and hoarding: how are they related? Knowl Manag Res Pract. https://doi. org/10.1080/14778238.2020.1774434

47. Webster J, Brown G, Zweig D, Connelly CE, Brodt S, Sitkin S (2008) Beyond knowledge sharing: withholding knowledge at work. In: Research in personnel and human resources management. Emerald Group Publishing Limited, pp 1-37

48. Williams KD (2007) Ostracism. Annu Rev Psychol 58:425-452

49. Wu CH, Liu J, Kwan HK, Lee C (2016) Why and when workplace ostracism inhibits organizational citizenship behaviors: an organizational identification perspective. J Appl Psychol 101(3):362

50. Wu LZ, Yim FHK, Kwan HK, Zhang X (2012) Coping with workplace ostracism: the roles of ingratiation and political skill in employee psychological distress. J Manag Stud 49(1):178-199

51. Wynen J, Kleizen B, Verhoest K, Lægreid P, Rolland V (2020) Just keep silent... Defensive silence as a reaction to successive structural reforms. Public Manag Rev 22(4):498-526

52. Xu AJ, Loi R, Lam LW (2015) The bad boss takes it all: how abusive supervision and leader-member exchange interact to influence employee silence. Leadersh Q 26(5):763-774

53. Yang J, Treadway DC (2018) A social influence interpretation of workplace ostracism and counterproductive work behavior. J Bus Ethics 148(4):879-891

54. ZeithamI VA, Berry LL, Parasuraman A (1996) The behavioral consequences of service quality. J Market 60(2):31-46

55. Zhao H, Xia Q (2017) An examination of the curvilinear relationship between workplace ostracism and knowledge hoarding. Manag Decis 55(2):331-346

56. Zhao H, Xia Q, He P, Sheard G, Wan P (2016) Workplace ostracism and knowledge hiding in service organizations. Int J Hosp Manag 59:84-94

\section{Publisher's Note}

Springer Nature remains neutral with regard to jurisdictional claims in published maps and institutional affiliations. 